\title{
A pilot study: Facilitating cross-cultural understanding with project-based collaborative learning in an online environment
}

\author{
Rustam Shadiev \\ National Cheng Kung University \\ Wu-Yuin Hwang \\ National Central University \\ Yueh-Min Huang \\ National Cheng Kung University
}

\begin{abstract}
This study investigated three aspects: how project-based collaborative learning facilitates cross-cultural understanding; how students perceive project-based collaborative learning implementation in a collaborative cyber community (3C) online environment; and what types of communication among students are used. A qualitative case study approach was applied to explore these aspects using a variety of data sources. First, students' reflections were evaluated to determine their level of cross-cultural understanding. Second, students' messages on the discussion board were analysed to explore their cross-cultural learning process and types of communication. Third, interviews were conducted with the students and their instructor to investigate their experiences and perceptions with respect to projectbased cross-cultural learning. Results of this study show that cross-cultural learning took place in the $3 \mathrm{C}$ online environment. Folk games, learning activities, were interesting, drew students' attention, and stimulated their motivation. The students and the instructor positively perceived the $3 \mathrm{C}$ online environment as it created an authentic learning environment by connecting students from different cultures. Educational, technical, and communicative types of communication in the $3 \mathrm{C}$ environment were derived; however, only communication of the educational type could facilitate cross-cultural understanding. Based on the results, this study provides implications and suggestions for the teaching and research community in the field.
\end{abstract}

\section{Introduction}

Cross-cultural understanding has become critical to a country's cultural, technological, economic, and political welfare (Bartell, 2003; Bernáld, Cajander, Daniels, \& Laxer, 2011). Therefore, it is essential for universities nowadays to educate, or more importantly, transform, to function effectively and comfortably in a world characterised by close multifaceted relationships and permeable borders. Students must possess a certain level of global competence to understand the world they live in and how they fit in this world.

A considerable amount of literature has been published on cross-cultural understanding and how to promote it. Most of studies on cross-cultural learning argue that individuals understand different cultures, languages, and traditions of other countries through communication and sharing information with others, particularly with members of the host culture. Moreover, essential learning behaviours that lead to crosscultural understanding, such as regularly interacting with others, expressing interest for the host culture, spending time studying the host culture, understanding ambiguous situations and making sense of new experiences, were introduced by Yamazaki and Kayes (2004). However, not much attention was paid in the literature on administering cross-cultural learning in an authentic learning environment where students representing different cultures around the world and from different locations can connect online. Moreover, it is still unclear how to bring out the motivation of students who are unacquainted or do not know each other well to communicate and share information with one another or how to foster their learning behaviours (Rakhmonkulova \& Shadiev, 2006) as proposed by Yamazaki and Kayes (2004) and mentioned above.

It is suggested that project-based learning (PBL) can benefit one's overall learning as well as one's crosscultural understanding. Due to rapid technological development, the availability of technology, and its applications for PBL, students have extended capacity for research and analysis. Besides, modern technology creates an online collaborative learning environment. Such environment is suitable for cross- 
cultural learning as it provides an opportunity for geographically dispersed students to learn together about each other's culture through communication and information sharing (Chen, Ko, Kinshuk, \& Lin, 2005; Hwang, Shadiev, Kuo, \& Chen, 2012; Kuo, Shadiev, Hwang, \& Chen, 2012; Tu, 2004). However, technology in most studies on PBL was used to explore project-related information on the Internet, develop computer-based models, and conduct simulations and lab experiments. The literature reveals that not much attention was paid to investigating a PBL activity implemented in a collaborative online environment, and how it facilitates cross-cultural understanding. Moreover, little is known about what benefits PBL in a collaborative online environment may have in increasing students' cross-cultural understanding.

Guided by cross-cultural understanding theory and PBL pedagogical approach, this study designed a project-based learning activity to facilitate students' cross-cultural understanding. Students from different cultures and locations around the world gathered together in convenient online classrooms and made the learning environment authentic; meanwhile the learning activity fostered students' interaction to collaborate on the activity and to experience the authentic cultures of peers. A project, such as a folk game, centring on an interesting topic, piqued students' interest and stimulated their motivation. A folk game is a traditional game used as a physical and/or mental exercise and which represents culture, language, and traditions of a player's own or his/her peer's country. This study aimed to address the following research questions:

(1) How can cross-cultural learning take place in a 3C online environment through project-based collaborative learning?

(2) What are students' perceptions of project-based collaborative learning in a $3 \mathrm{C}$ online environment?

(3) What types of students' communication happened in project-based collaborative learning in a 3C online environment?

\section{Literature review}

\section{Cross-cultural understanding and folk games}

National culture is formed over many years and reflects a country's history, geography, sociology, language, and religion. The basic ability of individuals to understand different cultures, history, languages, and traditions of other countries is referred to as cross-cultural understanding. In the field of cross-cultural understanding, various theories have been proposed, and of particular interest to this study is cultural convergence theory (Gudykunst, Ting-Toomey, \& Chua, 1988; Kincaid, 1979). Cultural convergence theory suggests that two or more individuals reach a mutual understanding of each other and the world in which they live through communication and information sharing. That is, individuals may converge towards a more mutual understanding of each other's meaning through information exchange (Gudykunst et al., 1988; Kincaid, 1979).

Yamazaki and Kayes (2004) suggested that cross-cultural learning is a process that enables individuals to acquire new knowledge, skills, and techniques as well as to absorb new attitudes and values with respect to different cultures as a result of the experience and participation. Traditionally, cross-cultural education in a school is based on textbooks and an instructor's knowledge and experiences. Bloom and Johnston (2010) claimed that neither source can provide a thorough and authentic cross-cultural education. One reason is that textbooks are often biased and mostly present the views of the dominant class. Another reason is that teachers may be biased toward sother cultures, or they may have only limited cross-cultural knowledge and/or experiences. Bloom and Johnston (2010) suggested administering cross-cultural programs as united, connected events, and as a knowledge-building continuum. Yamazaki and Kayes (2004) underlined essential behaviours of learners that lead to their cross-cultural understanding:

(1) building relationships - interacting with others regularly, particularly with members of the host culture

(2) valuing people of different cultures - expressing interest and respect for the host culture, including its history, customs, and beliefs

(3) listing and observing - spending time observing, reading about, and studying the host culture, particularly with members of the host culture 
(4) coping with ambiguity - understanding ambiguous situations and making sense of new experiences

(5) translating complex information - translating personal thoughts into the language of the host culture.

Various learning activities have also been proposed in the literature to facilitate cross-cultural understanding. Chase, Macfadyen, Reeder, and Roche (2002), Curtis and Lawson (2001), Liu (2007), and $\mathrm{Tu}$ (2004) emphasised the importance of self-introduction in online courses. They argued that selfintroduction is a necessary activity for students to become acquainted with one another and their cultures (Liu, 2007; Tu, 2004). Self-introduction reinforces the comfort level in an online classroom and encourages more social interactions (Curtis \& Lawson, 2001). Self-introductions help students to identify and to examine some of their own and peers' cultural values (Chase et al., 2002). Through creating media content, sharing it, and interacting with others, students get opportunities for peer-to-peer learning, diversification of cultural expression, and a more empowered cross-cultural conception (Jenkins, Purushotma, Weigel, Clinton, \& Robison, 2009). According to Jenkins et al. (2009), social networking allows students to search for, to synthesise, and to disseminate information while negotiation enables students to discern and to respect multiple perspectives across diverse communities. Through play, performance, and appropriation, students adopt alternative identities and sample and remix media content meaningfully for the purpose of improvisation and discovery (Jenkins et al., 2009). According to Bloom and Johnston (2010), students from various cultures who share their ideas, artifacts, and perspectives with one another can introduce their own culture as well as experience the foreign culture. Thus, presenting a cultural project allows students to share their experiences with peers and interact with other students through questions and answers. Additionally, it enables students to gain a better understanding of the strengths and weaknesses of a project (Tu, 2004).

A folk game is commonly used as a physical and/or mental exercise, for enjoyment, and as an educational tool. Different folk games exist in different cultures and they are passed along informally from one generation to another. Mahjong is one example of a folk game. This game has been commonly played in Chinese culture for several centuries. Usually friends and family members play mahjong for fun during important cultural events, that is, the Chinese New Year. A folk game reflects the values and beliefs of its parent culture (Brunvand, 1998; Hartzog, 1996). Thus, a folk game can be an appropriate learning activity to appeal to students and to stimulate their motivation through communication with each other and information sharing.

\section{PBL}

PBL is a constructivist-based instructional approach designed to guarantee more learning engagement (Krajcik \& Blumenfeld, 2006). This approach uses projects as vehicles to promote students' motivation and to provide a means for demonstrating and explaining what was learned. According to Rakhmonkulova and Shadiev (2006), projects are complex tasks, and students need to challenge, to question, to design and to investigate. Projects also give students the opportunity to work relatively autonomously over extended periods of time and to develop realistic products or presentations (Shadiev, 2007).

Evidence suggested that PBL has a positive effect on students' content knowledge (Shadiev, 2007), the development of skills such as collaboration, critical thinking, and problem solving (Mergendoller, Maxwell, \& Bellisimo, 2006; Rakhmonkulova \& Shadiev, 2006). In addition, students involved in PBL activities maintain higher learning motivation (Krajcik \& Blumenfeld, 2006) and engagement (Brush \& Saye, 2008). However, Brush and Saye (2008) claimed that PBL is challenging for teachers to implement; teachers need support for planning and enacting PBL effectively, while students need support to set up and direct initial inquiry, organise their time to complete tasks, and integrate technology into projects in meaningful ways.

According to Krajcik and Blumenfeld (2006) and Oracle Education Foundation (2009), PBL focuses how learners drive questions, situate inquiry, collaborate, and create artifacts. PBL organises the act of learning around driving questions. Everything students do is to focus on answering such questions through investigations, computer work, library research, discussions. Students pursue solutions to authentic problems by asking and refining questions, making predictions, designing plans, gathering 
information, collecting and analysing data, and drawing conclusions. Students involved in PBL collaborate with one another by sharing their ideas and findings. Artifacts represent the students' knowledge and understanding of driving questions, which are often communicated to a real-world audience. Integrating technology to support learning and create artifacts is another important feature of PBL. Krajcik and Blumenfeld (2006), Shadiev (2007), and Oracle Education Foundation (2009) suggested that the use of technology extends students' capacity for research, analysis, and collaboration. For example, telecommunications allow students to interact with a wider community of other students, and outside science experts can easily share information, data, resources, and ideas via telecommunications services (Hwang, Chen, Shadiev, Huang, \& Chen, 2014). Computers and the Internet help authenticate a learning environment because technology provides access to data and information, promotes investigation, and offers tools for producing artifacts (Shadiev et al., 2014). In the Water Quality Project, students used computer technology to develop models that show how various factors influence water quality (Krajcik \& Blumenfeld, 2006). Students in the Save our Lagoon and Forest Fires projects explored Internet resources related to environmental issues (Oracle Education Foundation, 2009). Yang and Chen (2007) reported that students in the Advanced Joint English Teaching project participated in several Internet-based language learning activities. As reported by Shadiev (2007), students explored and attempted to solve social issues of their local communities by using technology.

Shadiev (2007) and Oracle Education Foundation (2009) suggested that PBL has great potential to support essential behaviors underlined by Yamazaki and Kayes (2004) that lead to cross-cultural understanding. For example, PBL gives students the power to learn on their own terms and the opportunity to access various perspectives. Students from different parts of the world who engage in PBL activities may increase their awareness of cultural differences through active participation and communication. Bloom and Johnston (2010) emphasised that learning can and should only occur in the context of active relationships, as instances of communicating with others. When students work with partners who are different from themselves, they learn how to resolve misunderstandings and overcome cultural barriers.

\section{Method}

\section{Research framework}

The research framework of this study is presented in Figure 1. Informed by the related literature on crosscultural understanding and PBL, this study designed a learning activity to facilitate cross-cultural understanding. The following four steps were included in the learning activity:

(1) Self-introduction (Chase et al., 2002; Curtis \& Lawson, 2001; Liu, 2007; Tu, 2004)

(2) Introducing a folk game (Jenkins et al., 2009)

(3) Play a game (Jenkins et al., 2009)

(4) Online face-to-face meeting (Bloom \& Johnston, 2010; Tu, 2004).

Culture was defined in this study as national culture that represents the culture, history, language, and traditions of participants from different countries around the world. Folk games were selected for a learning activity to appeal students and to stimulate their motivation. Besides, folk games require participants' communication and information sharing, which are emphasised by Gudykunst et al. (1988), Kincaid (1979), and Yamazaki and Kayes (2004) as the important attributes of cross-cultural learning. Key features of PBL (Krajcik \& Blumenfeld, 2006) were introduced to foster participants' learning, interaction, and collaboration. We created an authentic learning environment by connecting representatives of different cultures around the world and from different locations online. This study assumed that students from diverse cultures could learn about the culture of others by participating in our proposed activity via exchanging information about and playing/experiencing folk games. After the crosscultural learning activity, we gathered data in an effort to find answers to the research questions of this study. 


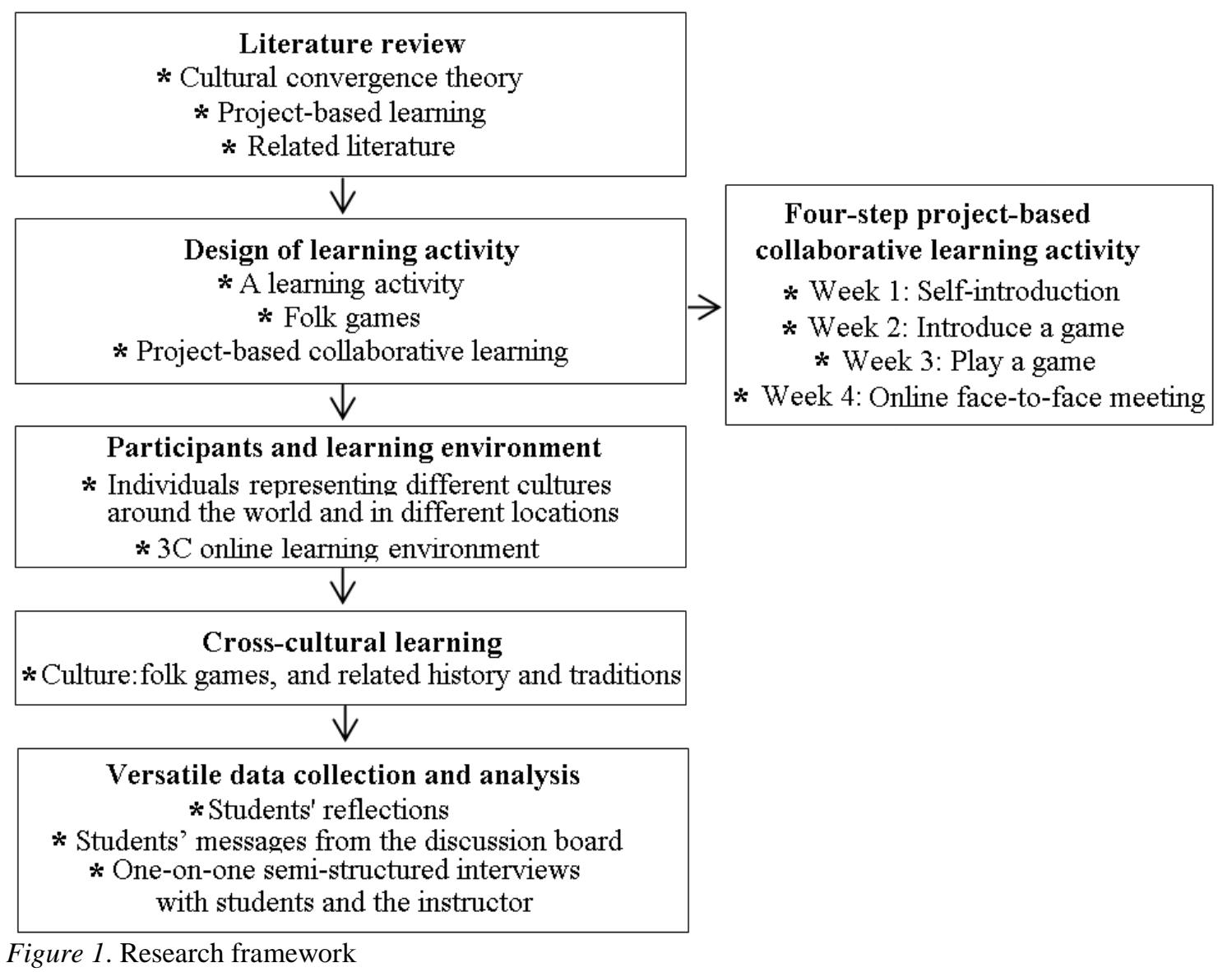

\section{PBCL activity}

A learning activity was divided into four 1-week steps. During the first week of this study, students posted self-introductions on the discussion board (Appendix A). Students introduced themselves, where they came from, their interests and favourite folk games. They mentioned in posts why the introduced games were special to them and how the games related to the local cultures. Students took pictures (e.g., family members playing folk games) and attached them to posts to make the self-introductions more meaningful and informative. Students then read others' posts and commented on them or asked for additional information regarding peers' backgrounds, folk games, and cultures.

In the second week, students formulated driving questions (e.g., What are the most popular folk games of my country? How did these games emerge in my country? Why are these games important to the local community?). To answer those questions, students looked for information on the Internet and in local libraries, and by surveying their friends and relatives. Explored information was then shared with peers on a discussion board (Appendix B). Each student introduced at least one folk game, which was then explored by peers. Students who were interested in a specific folk game or related culture wrote comments to or asked for additional information from the peer who introduced it.

During the third week, each student chose one of the folk games posted (Appendix C). Students formulated driving questions again (i.e., What are the most popular folk games of my peers? How did these games emerge in their country? Why are they important for the community?) and tried to answer them by reading peers' posts, asking them questions, and looking for additional information on the Internet. Students had their own motivation for their choice: some wanted to learn more about a certain foreign culture, and some tried to challenge their skills by playing a folk game. Students also considered the availability of a game to play; for example, some folk games can be found on the Internet and played online, and some folk games are so popular that they can be purchased anywhere. After a student picked a game, he/she wrote about his/her choice on the discussion board. In this case, a student introduced a 
game, and the students who chose it could communicate with one another regarding the game, its rules, and cultural background. Students shared their reflections and experience regarding playing a game on the discussion board; peers commented on these posts and/or asked questions.

In the fourth week, students met face-to-face in the online synchronous cyber classroom. Before the meeting, each student created PowerPoint ${ }^{\circledR}$ slides that were presented to peers on the day of the meeting. Slides included information about a folk game that a student played and related history and traditions. Besides, students included their experiences and reflections upon participation in the project-based communicative learning (PBCL) activity in their slides. Therefore, slides represented students' knowledge and understanding of the driving questions.

The PBCL activity was designed with key features proposed by Krajcik and Blumenfeld (2006). The folk games project featured driving questions that were formulated by the students in the second and third weeks. The students were involved in a situated inquiry to investigate their own and peers' folk games. They collaborated with one another by exchanging information and opinions regarding their own and peers' folk games. All students created artifacts at the end of the activity. In addition, technology was employed to collect information, collaborate with others, and create and present artifacts. Projects with the above-mentioned key features were carried out in the studies of Krajcik and Blumenfeld (2006), Oracle Education Foundation (2009), Shadiev (2007), and Yang and Chen (2007). However, this study took an innovative approach to carry out a four-step activity of PBL in a 3C online learning environment in order to promote cross-cultural understanding. This was unique compared to other related studies.

\section{Participants}

Seven students (four males and three females) between the ages of 20 and 35 voluntarily participated in this study. None of the participants had any previous experience with PBCL, nor had they experienced using a $3 \mathrm{C}$ environment. However, all students had more than 5 years' experience using computers and the Internet. Table 1 shows the nationality of the students and their choice of folk games to play. This study renamed the participants to protect their identity due to ethical issues; therefore, for the remainder of this paper, students will be referred by their IDs. All participants declared that they had no prior knowledge about the selected games and related history and traditions. An instructor with more than 10 years of experience in delivering online courses guided the PBCL process in this study. At the beginning of the project, an instructor described the steps of the learning activity on the discussion board and invited students to participate. Students were taught how to communicate project-related information (e.g., selfintroduction or game introduction) to others efficiently and they were reminded of the important deadlines. Furthermore, during the activity, an instructor guided students on how to use the 3C online environment and provided immediate assistance in troubleshooting technical problems.

Table 1

\begin{tabular}{lll}
\multicolumn{2}{l}{ Nationality of the participants and games } \\
\hline Student ID & Nationality & Selected game (nationality representing the game) \\
\hline S1 & Mongolia & Chinese checkers (Taiwan) \\
S2 & Taiwan & Backgammon (Uzbekistan) \\
S3 & Uzbekistan & Onisom Togloom (Mongolia) \\
S4 & Taiwan & Yahtzee (Australia) \\
S5 & Guatemala & Chinese checkers (Taiwan) \\
S6 & Australia & The Guatemalan lottery (Guatemala) \\
S7 & Taiwan & Onisom Togloom (Mongolia) \\
\hline
\end{tabular}

\section{Online learning environment}

Proposed by Chen et al. (2005), a 3C learning environment features asynchronous and synchronous cyber classrooms which are accessible by an instructor and students. The asynchronous environment (i.e., discussion board) was employed in this study as a learning space for the students' written communications; to continue social conversation and to share personal information at convenient times (Tu, 2004). The synchronous environment created by the JoinNet ${ }^{\mathrm{TM}}$ application features audio and video interaction, versatile synchronous information-sharing tools, and a control panel. Students could upload and present PowerPoint ${ }^{\circledR}$ slides using the whiteboard and interact with peers in the synchronous cyber classroom (Hwang et al., 2012; Kuo et al., 2012). Detailed discussions of the 3C environment and its 
features for asynchronous and synchronous communication can be found in Chen et al. (2005). Researchers instructed students on how to use the $3 \mathrm{C}$ environment before beginning the activity.

\section{Data collection and analysis}

This study collected the data which was obtained from students' online asynchronous and synchronous communication and from one-on-one semi-structured interviews. Students' reflections during the online face-to-face meeting were evaluated first to determine their level of cognition with regard to crosscultural learning. The evaluation covered three dimensions: (1) a folk game, (2) related history, and (3) traditions, and it was carried out by employing Krathwohl's (2002) six-level taxonomy. The taxonomy includes the following six levels of cognition and the corresponding definitions:

(1) Remember (retrieve relevant knowledge from long-term memory)

(2) Understand (construct meaning from instructional messages, including oral, written, and graphic communication)

(3) Apply (carry out or use a procedure in a given situation)

(4) Analyse (break material into its constituent parts and determine how the parts relate to one another and to an overall structure or purpose)

(5) Evaluate (make judgments based on criteria and standards)

(6) Create (put elements together to form a novel, coherent whole or to make an original product).

The study adopted a concept as a coding unit and 6-point scales for the assessment. A score of 1 represented the lowest level of cognition, and a score of 6 represented the highest level. Three raters were involved in the evaluation process. The inter-rater reliability coefficients among them were calculated using Cohen's kappa (Creswell, 2012). The mean inter-rater reliability among the three raters exceeded 0.80 , which demonstrates excellent agreement beyond chance.

This study collected all students' messages from the discussion board of the $3 \mathrm{C}$ environment to explore students' reflections on played games and related culture, and their communication with peers.

At the end of the activity, in-depth, one-on-one semi-structured interviews were conducted (Gaskell, 2000) with each student and the instructor. Lievens, Harris, Van Keer, and Bisqueret (2003) suggested that interviews are a suitable tool for measuring cross-cultural understanding. The interviews contained open-ended questions in which students and the instructor were asked about their PBCL experience in an online environment during this study, opinions about facilitating cross-cultural understanding with the four-step project, and perceptions regarding the 3C online environment to support cross-cultural PBCL. Each interview took approximately 30 minutes.

Students' online synchronous communication and interviews were audio-recorded with their permission and then fully transcribed for analysis. Following the general recommendations of Creswell (2012), text segments in transcripts and in students' messages from the discussion board of the $3 \mathrm{C}$ environment that met the criteria for providing the best research information were highlighted and coded. Codes were then sorted to form categories; codes with similar meanings were aggregated together. Established categories produced a framework for reporting findings to the research questions. Three raters were involved in the coding process, and big differences in the coding were resolved through raters' discussions and by consensus. Cohen's kappa was adopted to evaluate the inter-rater reliability; the result exceeded 0.80 , which indicates high reliability.

The small sample size of this study may limit the generalisation of the results. However, this study used a longitudinal approach to enhance the accuracy and credibility of its results (Creswell, 2012; Gaskell, 2000). First, our sample was designed to provide a detailed, close-up or meticulous view of the process of facilitating cross-cultural understanding through PBCL in a 3C online environment (Williams, 2000). Second, this study followed the case study logic discussed by Small (2009), and our participants represented not a small sample, but a set of meaningful cases with particular characteristics that should be understood deeper, developed, and incorporated into our understanding of the cases at hand. Third, this study obtained evidence from different students and the instructor, and it used different methods of data collection, which allowed triangulating among different data sources (Creswell, 2012; Gaskell, 2000). 
Therefore, the saturation (i.e., depth of understanding and experience) was more important in this study than commonality or generalisation across a sizeable sample.

\section{Results and discussion}

\section{Facilitating cross-cultural learning through a $\mathrm{PBCL}$ approach in the $3 \mathrm{C}$ online environment}

All participants claimed that they had no prior knowledge about the chosen games and their history and traditions before this study. However, results of the evaluation of the online face-to-face presentations reveal that students' cognition reached at least understand level. According to Krathwohl (2002), understand level represents the ability of a student to grasp the meaning of the learning material. It was shown that students could interpret, summarise, compare and explain the material. In this case, the learning goes beyond rote recall. Extracts of students' statements with key concepts about a folk game and its related history and traditions were taken from the content of students' oral presentations and included in Table 2. The statements indicate that student 1 understood Chinese checkers and student 4 knew how to play Yahtzee. The next statements made by student 2 and student 7 indicate their understanding of history related to backgammon and Mongolian onison togloom respectively. The statement of student 5 demonstrates that he understood the traditions of the game, and the statement of student 6 shows that he learned some new Spanish vocabulary and the traditions of Guatemalan culture while playing Loteria. These results suggest that cross-cultural learning took place through the PBCL activity in the $3 \mathrm{C}$ online environment.

To validate this research finding, the present study carried out interviews with the students and instructor. According to the interviews, students thought that the four-step PBCL activity facilitated their crosscultural understanding. Students mentioned that the self-introduction was a useful step in the activity. They could read others' posts on the discussion board to become acquainted with one another (Liu, 2007; $\mathrm{Tu}, 2004)$ and with peers' cultures. They could identify some cultural differences as well (Chase et al., 2002).

Furthermore, if students were interested in the particular details of a game, they could ask questions or look for answers on the Internet. Students admitted that it was easier to communicate with peers whom they had never met before using the asynchronous communication of the 3C online environment. According to students' opinions, asynchronous communication could help them ease anxiety and inhibition, and it motivated them to disclose personal information more frequently and more effectively than they usually would during face-to-face interactions (Yang \& Chen, 2007). This finding is in line with other related studies. Liu (2007) and Tu (2004) argued that self-introduction is a necessary activity for students to become acquainted with one another and their cultures. Through introductions, students identify and examine some of their own and peers' cultural values (Chase et al., 2002). 
Table 2

Key concepts related to a folk game, its history, and associated cultural traditions

\begin{tabular}{|c|c|c|}
\hline Student ID & Statement & Dimension \\
\hline S1 & $\begin{array}{l}\text { Chinese checkers is a board game played by two to six people. A player needs to } \\
\text { move all of his checkers from one corner to an opposite corner. Players take } \\
\text { turns to move checkers and they have to be moved to an adjacent unoccupied } \\
\text { space. }\end{array}$ & A folk game \\
\hline S3 & $\begin{array}{l}\text { Onison togloom is the Mongolian puzzle game. It consists of six to nine wooden } \\
\text { parts that need to be assembled in one very specific and uneasy way. After all } \\
\text { parts are assembled, the puzzle will be locked. So it is very challenging to } \\
\text { assemble and resemble Onison togloom. }\end{array}$ & A folk game \\
\hline S4 & $\begin{array}{l}\text { At the beginning, I thought Yahtzee is similar to Monopoly since both of them } \\
\text { are dice game. However, later I found there are so many differences between } \\
\text { them. In Yahtzee you need to score the most points by rolling dices to make } \\
\text { certain combinations but in Monopoly you move around the board buying, } \\
\text { selling or renting properties. }\end{array}$ & A folk game \\
\hline S2 & $\begin{array}{l}\text { One of the well-known and ancient games in Central Asia is Backgammon. } \\
\text { According to the legend, this game was originated more than 5,000 years ago and } \\
\text { it was designed to train and test sharpness of players. }\end{array}$ & $\begin{array}{l}\text { Related } \\
\text { history }\end{array}$ \\
\hline S7 & $\begin{array}{l}\text { Onison togloom is an ancient Mongolian game; it is even older than nomadic } \\
\text { tribe of Mongolia. Through learning about and playing Onisom Togloom game I } \\
\text { could find that Mongol are nomadic and they have moved from one place to } \\
\text { another in the past. Therefore I can understand the reason why this game was } \\
\text { invented - it taught Mongol visual representation and such skills as how to } \\
\text { assemble and reassemble their Ger (i.e. mobile houses) fast and build them } \\
\text { stable. }\end{array}$ & $\begin{array}{l}\text { Related } \\
\text { history }\end{array}$ \\
\hline S5 & $\begin{array}{l}\text { Chinese checkers is a very popular game in Taiwan. I found that friends or } \\
\text { family members gather together at a big meal dedicated to some important } \\
\text { holydays, such as Chinese new year or Moon festival and they play the game } \\
\text { after it. Playing the game gives them a good chance to chat about important } \\
\text { events and plans in their life. }\end{array}$ & $\begin{array}{l}\text { Related } \\
\text { traditions }\end{array}$ \\
\hline S6 & $\begin{array}{l}\text { I learned some new Spanish vocabularies and riddles from Loteria cards (e.g. El } \\
\text { gallo, El borracho or El negrito) as you need to speak them out to tell the players } \\
\text { which card was drawn. I also learned the way to speak out each card with } \\
\text { specific intonation. This game is so popular in Guatemala so that many families } \\
\text { are used to gather in a big groups, sitting around a table, for a meal and then to } \\
\text { play this game. They enjoy chatting with one another, making jokes, laughing, } \\
\text { screaming, and having a good time together. }\end{array}$ & $\begin{array}{l}\text { Related } \\
\text { traditions }\end{array}$ \\
\hline
\end{tabular}

In the interviews, students reported that during the second and third weeks they could learn more about their own and peers' folk games and cultures. For example, students could explore new facts about folk games from their own country and culture that they did not know before the activity. Students preferred to create unique content with their findings and to share it with others (Bloom \& Johnston, 2010; Jenkins et al., 2009). Students confirmed that they could learn about foreign folk games and their culture by playing these games, reading peers' posts, and finding additional information on the Internet. Moreover, students mentioned that they could compare folk games from their own country with foreign ones and find some similarities and differences; it was so exciting to explore the importance of folk games to communities, particularly the reasons behind the invention of these games (Oracle Education Foundation, 2009). The following comments are from two interviews.

\section{Student S1:}

I learned other country's culture by reading posts of my peers and playing their folk games. When I have played a foreign game, another student explained in details about this games, history and rules. I think this way is efficient to learn about another country's culture and traditions.

\section{Student S3:}

It was interesting and enjoyable experience. From my Mongolian peer I learned not only about her game but related culture as well. Like, third population of Mongolia still shares nomadic tradition. Mongolians travel with their livestock over the immense grasslands several times per year. This can explain why Onison togloom is so important for them. 


\section{Student S6:}

I think there were games which were good to share your culture, like Student S5's game. When I played that game, I really could learn a lot, because there is a lot of pictures, and Spain words, and Student S5 could tell me like the way to talk about different thing in his game... the background behind the game is the interesting part of this activity.

The present findings seem to be consistent with other research. Creating media content, sharing it, and interacting with others are potential activities that provide opportunities for peer-to-peer learning, diversification of cultural expression, a more empowered conception of citizenship, and also facilitation of cross-cultural understanding (Jenkins et al., 2009). Jenkins et al. (2009) suggested that networking allows one to search for, synthesise, and disseminate information; negotiation allows one to travel across diverse communities, discern and respect multiple perspectives, and grasp and follow alternative norms. The activities of play, performance, and appropriation enable students to experiment with their surroundings and to adopt alternative identities and sample and remix media content meaningfully for the purpose of improvisation and discovery (Jenkins et al., 2009). According to Bloom and Johnston (2010), students from various cultures can introduce and experience foreign culture to develop their cross-cultural understanding and to broaden their worldviews as they share ideas, images, and perspectives with one another throughout the exchange.

In interviews, students mentioned that the online face-to-face meeting in the fourth week was useful for the goals of the project. First, students could finally meet peers with whom they collaborated throughout the project and present their experiences and reflections regarding folk games and relevant cultures (Yang \& Chen, 2007). Second, students could interact with one another synchronously (Tu, 2004) to share their experiences and reflections regarding the activity, ask/answer questions, and give/receive instant comments. Third, students could get first-hand cultural experience as they were communicating face-toface with the ones who introduced the games and represented the culture related to the games. This finding is in agreement with those of Tu (2004) and Salmon (2003). They argued that presenting a project allows students to share what they have completed with other participants, present their projects online, and defend them to peers. Such design provides a good opportunity to increase interaction among students through question and answer sessions. Additionally, it enables students to gain a better understanding of the strengths and weaknesses of a project (Salmon, 2003; Tu, 2004). The fact that the PBCL activity in the 3C environment was beneficial for students' cross-cultural learning was also confirmed by the instructor in the interviews. The instructor stated that each step of the activity helped students to give as well as to receive some useful information related to their own or peers' culture. The instructor confirmed that students' participation in the learning activity in the authentic learning environment led to their cross-cultural learning. That is, each student could understand others' folk games and related culture as well as explain rules of the selected game, its history and related traditions. Moreover, the instructor and most students expressed their willingness to participate in similar activities in the future.

This finding is consistent with cultural convergence theory. The theory states that in a relatively closed social system in which communication among members is unrestricted, the system as a whole will tend to converge over time towards a state of greater cultural uniformity (Gudykunst et al., 1988; Kincaid, 1979).

Various learning activities to facilitate cross-cultural understanding have been proposed in related studies (Bloom \& Johnston, 2010; Chase et al., 2002; Jenkins et al., 2009; Liu, 2007; Salmon, 2003; Tu, 2004). However, little attention has been paid to investigate the potential benefits of PBCL to facilitate crosscultural understanding, particularly that of individuals representing different cultures around the world and in different locations. This study conducted such a learning activity, which facilitated cross-cultural understanding with PBCL in the 3C online environment. Our findings may enrich the current state of knowledge, and they might be useful to the teaching and research communities in the field. 


\title{
Students' perceptions regarding the $3 \mathrm{C}$ online environment to support cross-cultural PCBL
}

In general, students and the instructor agreed that the $3 \mathrm{C}$ online environment was useful for the implementation of the activity as well as for interaction among participants from different locations. The 3C online environment connected students from different cultures around the world, and thus, an authentic learning environment was created. Students mentioned that due to asynchronous communication through the discussion board they had enough time to post their information, to read peers' posts, to think about their own answers, and to respond meaningfully. Moreover, as students were not acquainted with one another before this study, asynchronous communication helped them to decrease anxiety and inhibition, especially during the first week of the activity (Yang \& Chen, 2007). From the interviews, this study found that the synchronous cyber classroom connected students representing different cultures and locations together and enabled their synchronous communication. That is, students could meet peers from other cultures to exchange useful information about their culture and to experience their culture in real time (Tu, 2004). Some students reported that synchronous communication made them feel as though they were part of one group. The following are examples from the interviews.

\author{
Student S4: \\ My English is very poor and I am shy to communicate with foreigner, especially to \\ unacquainted ones, so I'm happy can connect with all of you in the virtual environment. \\ This environment made me feel more comfortable and my communication was more \\ meaningful.
}

Student S5:

I like collaborative environment of this project. I had no pressure to post my messages on discussion board and also read messages of others. Having enough time is good to read about games and culture of others and then write them meaningful comment. On the other hand, I like communicating face to face with participants in online classroom, you ask question and get prompt answer.

\section{Student S6:}

This environment was nice because many people can be online at same time, and you can also see the video from many different people, the slides and hear the audio.

During the interviews, some students and the instructor, however, revealed several technical issues related to the $3 \mathrm{C}$ environment. One student complained that some features of the environment were unavailable when using a Web browser other than Internet Explorer ${ }^{\circledR}$ so that she could not upload files. Another student experienced a problem with connecting video and audio systems correctly for the online face-toface meeting and he missed the beginning of the meeting. These and other similar issues were experienced by students in the 3C environment in other studies (Chen et al., 2005; Gedik, Kiraz, \& Ozden, 2013; Hwang et al., 2012; Kuo et al., 2012). Therefore, potential technical issues need to be considered in advance, and immediate technical support should be available for the instructor and students throughout the learning activity (Brush \& Saye, 2008; Krajcik \& Blumenfeld, 2006).

Based on the findings of this study, the answer to the second research question is that students positively perceived PBCL in the 3C online environment.

\section{Students' communication in the $3 \mathrm{C}$ online environment}

This study categorised communication into three type: educational, technical, and communicative (Table 3) to analyse students' asynchronous and synchronous communication in the $3 \mathrm{C}$ environment. The educational category included communication related to cross-cultural learning (e.g., introducing a folk game). The technical category included communication regarding how technology works in the $3 \mathrm{C}$ online environment (e.g., asking for assistance to upload files). This category also included communication related to providing technical support by the instructor or peers. The communicative category included the remaining interactions between the instructor and students that did not relate to the educational or technical categories. For example, the instructor presented the most common students' communicative queries (e.g., about important deadlines) along with his explanations or peers' communicative comments 
related to experiences in playing games (e.g., "It was cool!”). According to Table 3, only communication of the educational category could facilitate cross-cultural understanding. Rakhmonkulova and Shadiev (2006) argued that it is challenging in any online projects to make students who are unacquainted with one another communicate and share information or foster their cross-cultural learning behaviours. To address this issue, the four-step PBCL with the interesting topic (i.e., folk games) was designed in this study. Such an arrangement of PBCL and its appealing topic attracted students and stimulated their motivation. According to communication in the educational category, students in this study regularly communicated and shared information with one another during Weeks 1-4 (e.g., self-introduction, introduction of a game and related culture, questions and answers), spent time studying and playing host games during Weeks 2-3), and made sense of new experiences and reflected on them during Weeks 3-4. Students admitted that they performed these behaviours because the cross-cultural learning in this study was inherently interesting and enjoyable and it led to cross-cultural understanding. Ryan and Deci (2000) acknowledged such learning motivation as intrinsic and extrinsic motivation. According to Table 3, communication in the technical and communicative categories helped students to eliminate particular technical issues, as well as eased and improved the efficiency of student participation.

Table 3

Classification of communication

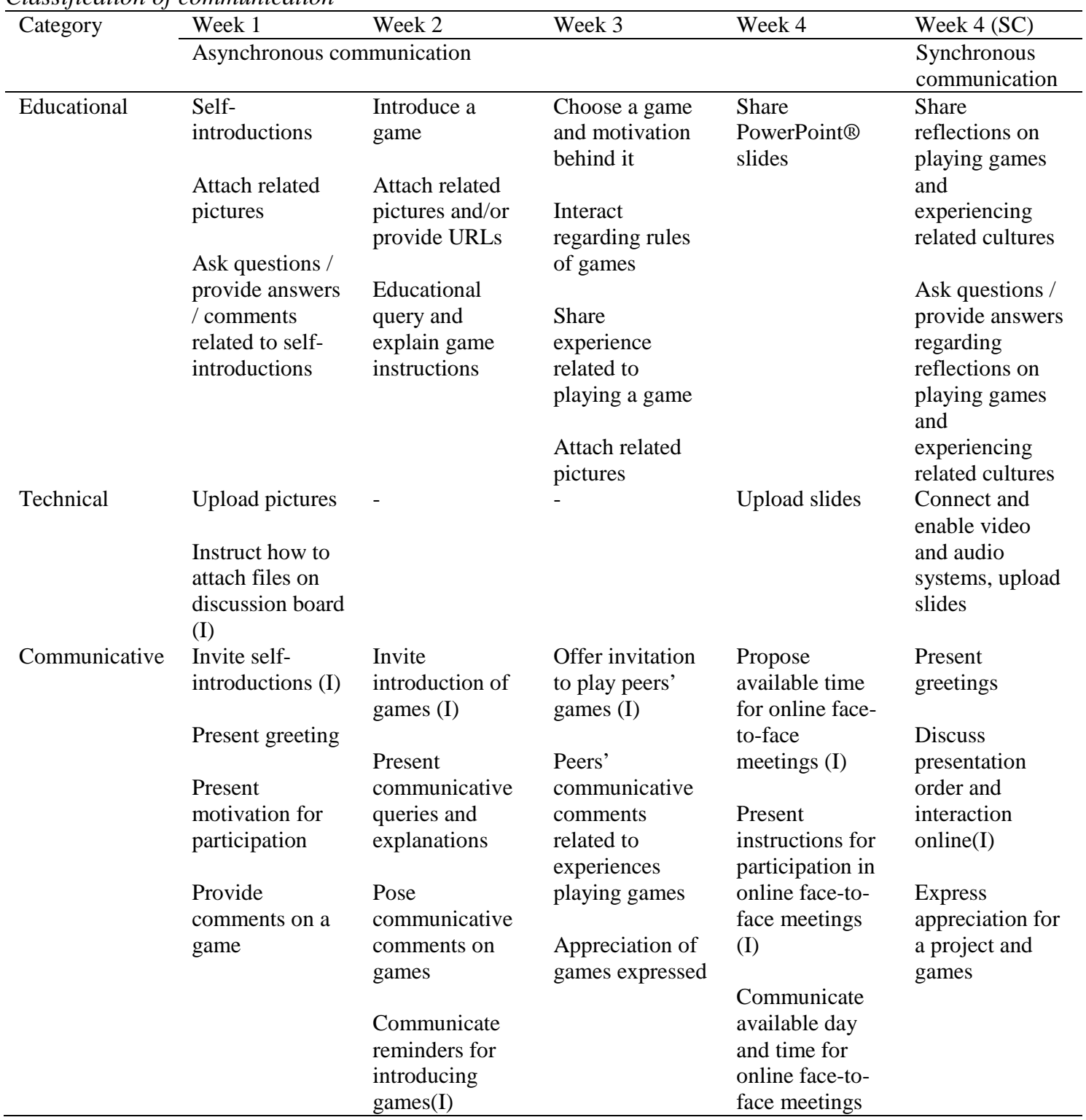

I: Posted by the instructor. 
Based on the results of this study, the answer to the third research question is that three types of communication among students, educational, technical, and communicative, happened in PBCL in a 3C online environment.

\section{Implications and suggestions}

This study provides several suggestions for teachers and those in the research community who design and conduct PBCL for online environments to facilitate cross-cultural understanding. First, this study suggests organising PBCL in four steps, such as those in the current study, that is, first, students introduce themselves and their culture; second, students introduce a folk game representing their culture; then students play folk games introduced by peers and experience peers' culture; finally, all students meet online face-to-face to present their experiences and reflections on the folk games and relevant cultures. This study also suggests focusing the project on an interesting topic, for example, related to foreign folk games and culture. This arrangement of PBCL and its appealing topic will attract students from different cultures and stimulate their motivation. Furthermore, it will facilitate students who are unacquainted to communicate and share information with one another, and promote the essential learning behaviors proposed by Yamazaki and Kayes (2004) to lead to cross-cultural understanding.

Second, this study suggests employing online cyber classrooms to create an authentic learning environment by connecting geographically dispersed students from different cultures around the world. Furthermore, students need to be encouraged to have more cross-cultural related communication (i.e., educational category). The asynchronous cyber classroom can be used to start communication (e.g., selfintroduction and own culture introduction) in the beginning of the activity when students are not acquainted with each other. It will help to diminish students' anxiety levels and allow them to get acquainted. Besides, students will have sufficient time to fully collect and investigate information to share as well as to study information shared by others. The synchronous cyber classroom can be introduced after students are well acquainted with each other. This will enable closer and more instant interaction between those who introduced the culture and those who experienced it. However, some potential technical issues in online cyber classrooms need to be considered, and timely technical support should be provided for the participants.

Third, this study suggests that the instructor should be familiar with the PBL pedagogical approach, welltrained in making good use of the $3 \mathrm{C}$ environment, and be aware of students' achievements and issues in order to efficiently moderate students' communications. Salmon's (2003) model was adopted in this study for e-moderated learning, and it can be used by others to support student engagement and learning online effectively. The 5-step model focuses on (a) access and motivation, (b) online socialisation, (c) information exchange, (d) knowledge construction, and (e) development. For example, according to the model, students need to be encouraged to communicate through posts with more meaningful content in order to enhance their cross-cultural understanding. It is also suggested that having a teaching assistant around during the activity would be effective to give remote students real-time assistance in solving issues related to their participation. One essential requirement to ensure the project's success is that students, especially those without prior PBL experience in the $3 \mathrm{C}$ online environment, need to be provided with timely and detailed guidelines. Guidelines of this study included the following items from Brush and Saye (2008), Gedik et al., 2013; Krajcik and Blumenfeld (2006), Parkes, Reading, and Stein (2013), and PBL Guide (2014):

- $\quad$ Structure - critical organising features of the project that determine who does what and when. For example, the instructor described each step of the project on the discussion board. The instructor asked students to introduce themselves, their country, the most famous folk games, and related culture during the first week. In the second week, the instructor asked students to choose games they like to play and talk about the features and rules of the games with students who introduced them. And so on.

- Content - a learning activity that covers the foundational concepts and standards that students need to know for the project. For example, the instructor introduced students to what a folk game is and what cultural meanings are behind the game.

- Training - explicit skill-building for students in collaborative project work. For example, students were taught how to communicate information about themselves, a game, and related culture to others efficiently. 
- Tools - the technological resources necessary to participate in a project. This study employed the 3C online environment. Students had no prior knowledge on how to use it; therefore, the instructor had to guide them to use it efficiently.

- Oversight - structured times for the instructor to observe students' progress and to motivate and mentor them. Based on students' progress, the instructor guided students to complete the project's steps in time, to post complete information on the discussion board, etc. It is important to notice that guidelines should be provided to all abovementioned items as each of them is essential for the sake of the project success.

\section{Conclusion}

Informed by cultural convergence theory, the PBL approach, and related literature, this study administered cross-cultural learning in an authentic learning environment created by connecting representatives of different cultures around the world and from different locations online. The learning activity fostered students to communicate and to share information with one another, to collaborate on the activity, and to experience the authentic cultures of peers. The project centred on an interesting topic, such as a folk game, to draw students' interest and to stimulate their motivation. This study shows that students' cross-cultural learning did take place.

Based on the results, this study concludes that in general, students claimed the activity was interesting; it stimulated their motivation and enhanced cross-cultural understanding. Students learned more about folk games and related cultures - both near their homes and afar. Students also thought that the $3 \mathrm{C}$ environment was useful for the implementation of the activity; the environment provided a suitable gathering place for students from diverse cultures and locations to communicate and experience the authentic culture of others. This study derived three categories of communication in the $3 \mathrm{C}$ environment, and it found that only communication in the educational category could facilitate cross-cultural understanding.

With respect to applicability of the results beyond this study, it is assumed that the innovative approach of this study can be easily extended and applied for different cases, for example, for intercultural adaption. Intercultural adaption is the notion which entails people from one culture (i.e., immigrants) moving to a different culture, usually learning the rules, societal norms, customs, and language of the new culture in order to adjust to and to accept the new standards (Kim, 2001). A learning activity with interesting topics guided by the PBL key features, similar to the one of this study, can be designed and administered for potential immigrants. Such an approach will well prepare them for adapting to the host culture before and after moving to it. An authentic learning environment can be created by connecting immigrants with natives of the host culture online to make the immigrants' learning more meaningful. This assumption will be tested in the future study. Furthermore, the future study will investigate the effects of the innovative approach presented in this study on participants' cognition of various domains. For example, will participants from different countries around the world extend their knowledge of world geography and/or foreign language(s) in addition to cross-cultural understanding through the innovative approach of this study? If this is accomplished, to what extent is it shown?

The results of this study may enrich the current state of knowledge, while the implications and suggestions might be useful for the teaching and research communities of the field. However, one limitation of this study needs to be acknowledged and addressed in the future. This study had a small sample of students and a short period of time allotted for the learning activity, which restricts generalisation of the results. The small number of students, however, covered the range of folk games and represented different cultures. In the future study, more students from different classrooms around the world will be involved; this will enable generalisation of the results and it will represent more games and cultures. 


\section{Acknowledgements}

This research is partially supported by the International Research-Intensive Center of Excellence Program of NTNU and the Ministry of Science and Technology of the Republic of China, Taiwan, under the grant numbers NSC 103-2911-I-003-301, NSC 102-3113-P-006-019-, NSC 101-2511-S-008-012-MY3, NSC 101-2511-S-008-013-MY3, and NSC 100-2511-S-006-015-MY3.

The authors would like to thank Dr. Nian-Shing Chen (Chair professor at the Department of Information Management in the National Sun Yat-sen University, Taiwan), Dr. Fei-Ching Chen (Professor at the Graduate Institute of Learning and Instruction in the National Central University, Taiwan) and Zhong-Qi Liu, Jia-Ling Zhang and Wei-Wang Chen (graduate students of the Institute of Network Learning Technology in the National Central University, Taiwan) for their valuable contribution to this study.

\section{References}

Bartell, M. (2003). Internationalization of universities: A university culture-based framework. Higher Education, 45(1), 43-70. http://dx.doi.org/10.1023/A:1021225514599

Bernáld, H., Cajander, Å., Daniels, M., \& Laxer, C. (2011). Reasoning about the value of cultural awareness in international collaboration. Journal of Applied Computing and Information Technology, 15(1).

Bloom, K., \& Johnston, K. M. (2010). Digging into YouTube videos: Using media literacy and participatory culture to promote cross-cultural understanding. Journal of Media Literacy Education, 2(2), 113-123.

Brunvand, J. H. (1998). The study of American folklore: An introduction. New York, NY: W. W. Norton.

Brush, T., \& Saye, J. (2008). The effects of multimedia-supported problem-based inquiry on student engagement, empathy, and assumptions about history. The Interdisciplinary Journal of Problembased Learning, 2(1), 21-56. http://dx.doi.org/10.7771/1541-5015.1052

Chase, M., Macfadyen, L., Reeder, K., \& Roche, J. (2002). Intercultural challenges in networked learning: Hard technologies meet soft skills. First Monday, 7(8). Retrieved from http://firstmonday.org/ojs/index.php/fm

Chen, N. S., Ko, H. C., Kinshuk, \& Lin, T. (2005). A model for synchronous learning using the Internet. Innovations in Education and Teaching International, 42(2), 181-194. http://dx.doi.org/10.1080/14703290500062599

Creswell, J.,W. (2012). Educational research: Planning, conducting, and evaluating quantitative and qualitative research. Upper Saddle Creek, NJ: Pearson Education.

Curtis, D. D., \& Lawson, M. J. (2001). Exploring collaborative online learning. Journal of Asynchronous Learning Networks, 5(1), 21-34.

Gaskell, G. (2000). Individual and group interviewing. In M. Bauer and G. Gaskell (Eds.), Qualitative researching with text, image and sound (pp. 38-56). London: Sage.

Gedik, N., Kiraz, E., \& Ozden, M. Y. (2013). Design of a blended learning environment: Considerations and implementation issues. Australasian Journal of Educational Technology, 29(1), 1-19. Retrieved from http://ascilite.org.au/ajet/submission/index.php/AJET/index

Gudykunst, W. B., Ting-Toomey, S., \& Chua, E. (1988). Culture and interpersonal communication. Newbury Park, CA: Sage.

Hartzog, M. (1996). Folk games. In R. Tyler (Ed.), The new handbook of Texas. Austin: The Texas State Historical Association.

Hwang, W. Y., Chen, H. S. L., Shadiev, R., Huang, R. Y. M., \& Chen, C. Y. (2014). Improving English as a foreign language writing in elementary schools using mobile devices in familiar situational contexts. Computer Assisted Language Learning, 27(5), 359-378.

Hwang, W. Y., Shadiev, R., Kuo, T. C. T., \& Chen, N. S. (2012). A study of speech to text recognition and its effect to synchronous learning. Journal of Educational Technology \& Society, 15(1), 367-380.

Jenkins, H., Purushotma, R., Weigel, M., Clinton, K., \& Robison, A. J. (2009). Confronting the challenges of participatory culture: Media education for the 21st century. Cambridge, MA: MIT Press.

Kim, Y. (2001). Becoming intercultural: An integrative theory of communication and cross-cultural adaptation. Thousand Oaks, CA: Sage. 
Kincaid, D. L. (1979). The convergence model of communication (East-West Communication Institute Paper Series 18). Honolulu:.East-West Center.

Krajcik, J. S., \& Blumenfeld, P. C. (2006). Project-based learning. In K. Sawyer (Ed.), Cambridge handbook of the learning sciences (pp. 317-334). Cambridge: Cambridge University Press.

Krathwohl, D. R. (2002). A revision of Bloom's taxonomy: An OVERVIEW. Theory into Practice, 41(4), 212-218.

Kuo, T. C. T., Shadiev, R., Hwang, W. Y., \& Chen, N. S. (2012). Effects of applying STR for group learning activities on learning performance in a synchronous cyber classroom. Computers \& Education, 58(1), 600-608. http://dx.doi.org/10.1016/j.compedu.2011.07.018

Lievens, F., Harris, M. M., Van Keer, E., \& Bisqueret, C. (2003). Predicting cross-cultural training performance: The validity of personality, cognitive ability, and dimensions measured by an assessment center and a behavior description interview. Journal of Applied Psychology, 88(3), 476489. http://dx.doi.org/10.1037/0021-9010.88.3.476

Liu, Y. (2007). Designing quality online education to promote cross-cultural understanding. In A. Edmundson (Ed.), Globalized e-learning cultural challenges (pp. 35-59). Hershey, PA: IGI Global. http://dx.doi/10.4018/978-1-59904-301-2.ch003

Mergendoller, J. R., Maxwell, N. L. \& Bellisimo, Y. (2006). The effectiveness of problem-based instruction: A comparative study of instructional methods and student characteristics. The Interdisciplinary Journal of Problem-based Learning, 1(2), 49-69. http://dx.doi.org/10.7771/1541$\underline{5015.1026}$

Oracle Education Foundation. (2009). The power of project learning with ThinkQuest. Redwood Shores, CA: Author. Retrieved from http://www.thinkquest.org/en/

Parkes, M., Reading, C., \& Stein, S. (2013). The competencies required for effective performance in a university e-learning environment. Australasian Journal of Educational Technology, 29(6), 777-791. Retrieved from http://ascilite.org.au/ajet/submission/index.php/AJET/index

PBL Guide. (2014). Retrieved from http://naf.org/files/PBL_Guide.pdf

Rakhmonkulova, S., \& Shadiev, R. (2006). Use of IT in educational institutions of Uzbekistan: Experience and perspectives. In Proceedings of the International Conference on Interactive Computer Aided Learning Conference [Compact disk file].

Ryan, R. M., \& Deci, E. L. (2000). Intrinsic and extrinsic motivations: Classic definitions and new directions. Contemporary Educational Psychology, 25(1), 54-67. http://dx.doi.org/10.1006/ceps.1999.1020

Salmon, G. (2003). E-moderating: The key to teaching and learning online. London: Kogan Page.

Shadiev, R. (2007). Informational technologies in solving the social issues of school communities in Uzbekistan. In Proceedings of the International Conference on Interactive Computer Aided Learning [Compact disk file].

Shadiev, R., Hwang, W. Y., Yeh, S. C., Yang, S. J. H., Wang, J. L., Lin, H., \& Hsu, G. L. (2014). Effects of unidirectional vs. reciprocal teaching strategies on web-based computer programming learning. Journal of Educational Computing Research, 50(1), 67-9. http://dx.doi.org/10.2190/EC.50.1.d

Small, M. L. (2009). “How many cases do I need?” On science and the logic of case selection in fieldbased research. Ethnography, 10(1), 5-38. http://dx.doi.org/10.1177/1466138108099586

$\mathrm{Tu}, \mathrm{C} . \mathrm{H}$. (2004). Online collaborative learning communities: Twenty-one designs to building an online collaborative learning community. Westport, CT: Greenwood.

Williams, M. (2000). Interpretivism and generalisation. Sociology, 34(2), 209-224. http://dx.doi.org/10.1177/S0038038500000146

Yang, S. C., \& Chen, Y. J. (2007). Technology-enhanced language learning: A case study. Computers in Human Behavior, 23, 860-879. http://dx.doi.org/10.1016/j.chb.2006.02.015

Yamazaki, Y., \& Kayes, D. C. (2004). An experiential approach to cross-cultural learning: A review and integration of competencies for successful expatriate adaptation. Academy of Management Learning \& Education, 3(4), 362-379. http://dx.doi.org/10.5465/AMLE.2004.15112543

\section{Appendix}

\section{A. Example posts related to self-introduction from a discussion board}

Student S4: 
My name is ---, and Chinese name is ---, I am a master student. I am from Keelung which is the most north city in Taiwan. Keelung is the place with raining almost the whole year, so some people call Keelung "rain city". Seafood in Keelung is famous and fresh, if you have chance to go to Keelung, be sure to try it.

My favorite folk game is the whipping top, I start to play it when I was 8-years-old, during the Chinese New year. I always contest with kids of neighborhood on whose top rotates for the longer time. If somebody have interest, we can exchange our experience.

\section{Student S3:}

From wikipedia I found Keelung is a port city. Actually, we have not any big sea, lake or river that allows us to have a port. Can you please write a couple of lines about life in a port city, I'm sure it has its advantages and disadvantages.

\section{B. Example posts related to a game introduction from a discussion board}

Student S2:

I want to introduce Mahjong. It is one popular gambling game of Chinese culture. Mahjong was invented long ago and there are so many arguments about its origin. In the past, Chinese usually played Mahjong for fun after harvest. In the different area, Mahjong has different rules. For example, in Taiwan, each person has 16 tiles while in Hong-Kong only 13 tiles.

Student S5:

We have our special version of bingo. The Guatemalan lottery is played with cardboards of nine images, each cardboard is different, bean or maize counts, and a person calling out aloud the name of the images: La Chalupa, El Borracho, El Catrín, La Campana, la calavera, etcetera...sorry...Spanish words...translating...the canoe, the drunk, the dandy, the bell, the skull, etc. Whoever gets all nine images called out and accounted for with beans or maize seeds wins the lottery, if, and only if they scream with all their lungs LO-TE-RIIIIAAAAA.

\section{Example posts related to a game selection from a discussion board}

Student S6:

I will select Guatemalan Bingo. It seems like an interesting way to learn about what is interesting in Guatemalan culture. Maybe I can even remember some Spanish vocabulary that is used in the game.

Student S7:

I would like to try ONISON TOGLOOM. I'm not very good at 3D puzzle, and I reluctant to play this kind of game when I was small. This time, I would like to give myself a challenge. I want to see if this game can help me develop the area which control 3D images in my brain.

Corresponding author: Wu-Yuin Hwang, wyhwang@cc.ncu.edu.tw

Australasian Journal of Educational Technology (C) 2015.

Please cite as: Shadiev, R., Hwang, W-Y., \& Huang, Y-M. (2015). A pilot study: Facilitating crosscultural understanding with project-based collaborative learning in an online environment. Australasian Journal of Educational Technology, 31(2), 123-139. 